\title{
Development of a multipurpose test rig - TAILTEST
}

\author{
Martin Oberthor ${ }^{1}$, Václav Horák ${ }^{1}$, and Roman Růžek ${ }^{1}$ \\ ${ }^{1}$ VZLU - Czech Aerosopace Research Centre, Strength of Structures Department, Beranovych 130, \\ Prague 9, 199 05, Czech Republic
}

\begin{abstract}
The paper discusses an innovative multipurpose test rig designed with the aim of full-scale rotorcraft fin verification. The developed test rig includes a load application mechanism able to distribute loads representative for rotorcraft tail structure. Both conventional metallic components and innovative thermoplastic composites are used in the rotorcraft tail structure. The test rig will be designed so that a variable stiffness of the fuselage to the fin joint is achieved. Verification of the new tail structure is supported by additional experiments and numerical analyses.
\end{abstract}

\section{Introduction}

Single main-rotor helicopters are the most common type of helicopter. They require antitorque and heading stabilisation, often accomplished by a tail rotor and a vertical tail fin connecting the tail rotor to the tail. Clean Sky 2, a public-private partnership between the European Commission and the European aeronautics industry, is driving the development of a low-weight rotorcraft tail utilising thermoplastics to decrease fuel consumption and $\mathrm{CO} 2$ emissions. The EU-funded TAILTEST project is developing a multipurpose test rig and numerical models to enable scientists to test tail fin and joining structures, both experimentally and via simulations. Outcomes will support the certification of the innovative tail fin and also enhance understanding and characterisation of novel joining technologies.

TAILTEST project [1] addresses the topic described in the Call for Proposals JTI-CS2-2018CFP09-AIR-02-74 for the development of a multipurpose test rig and validation of an innovative rotorcraft vertical tail. Figure 1 shows the position of the project with respect to the AIR-ITD.

VZLU has a long term experience with similarly project and composite structure experiments and numerical verification [2-8].

Among high-ranking TAILTEST objectives is included the development and manufacturing of a multipurpose test rig. The designed multipurpose test rig represents a load application mechanism able to apply loads representative for rotorcraft tail structure and allow various load cases introduction. Both conventional metallic components and innovative thermoplastic composites are used in the rotorcraft tail structure. The test rig is designed so that a variable stiffness of the fuselage to the fin joint can be achieved. Verification of the new tail test structure is supported by additional experiments and numerical analyses. Experimental work can be summarized into the building block diagram which is shown in Figure 2. 


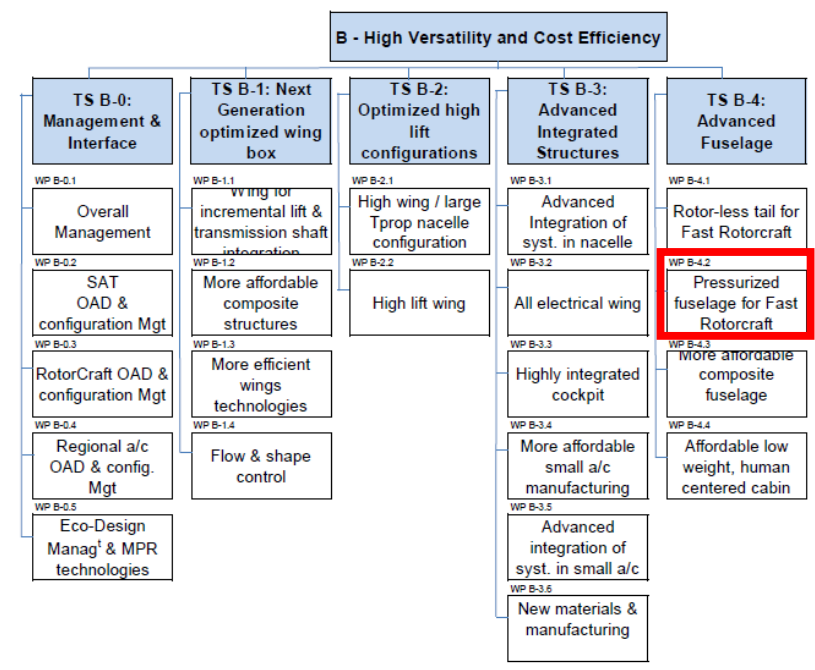

Fig. 1. TAILTEST project position of the project with respect to the AIR-ITD

The multipurpose test rig should be designed to meet several parameters - optimized attachment of the fuselage to ground support fixture, optimal loading of the fin and the dummy for $\mathrm{I} / \mathrm{F}$ loading and sufficient accessibility of the test rig for measuring systems and non-destructive testing.

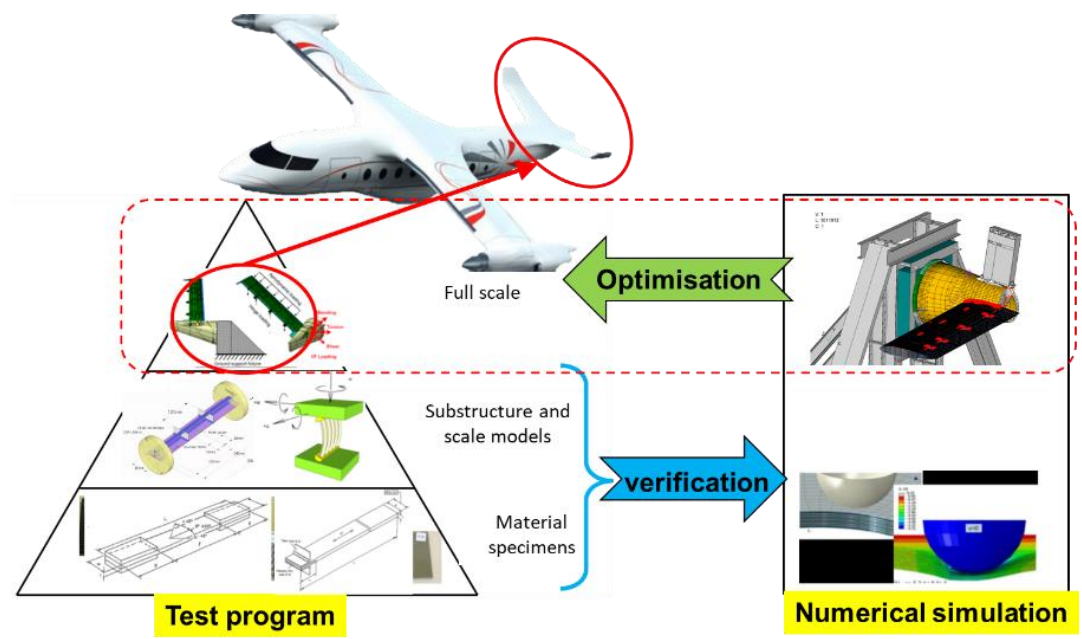

Fig. 2. Building block diagram for testing and numerical simulation

\section{Basic philosophy of the test}

The subject of the static test is the Fuselage with Fin LH (Left Hand). The Fin LH will be supplemented by the dummy Ruddervator LH, the Fin RH (Right Hand) will be substituted with the Dummy for I/F (Interface) Loading. The fuselage with the Fin LH will be attached to the VZLU test rig (Ground support structure), see Figure 2.

The multipurpose test rig shall be designed to meet several parameters:

- optimized attachment of the fuselage to ground support fixture;

- $\quad$ optimal loading of the fin and the dummy for interface (I/F) loading; 
- $\quad$ sufficient accessibility of the test rig for measuring systems and non-destructive testing.

Damage tolerance philosophy will be applied for fin part verification.

\section{Support of the test article}

The fuselage will be trimmed to a specific size for the static test. Next the fuselage will be connected to the VZLU test rig (Ground support structure) using the combined mechanical and glued attachment. The mechanical attachment consists of special aluminium inner contour boards, outer contour boards and stringer interfaces. A liquid shim (glue) will be added between the fuselage and the outer and inner contour boards, next the contour boards will be screwed together. The inner and outer contour board are shaped according to the fuselage. The basic view of the attachment is shown in Figure 3.

\section{Aft Tail-Section of NGCTR-TD Configuration Aft Tail-Section in Full-Scale Component Test}

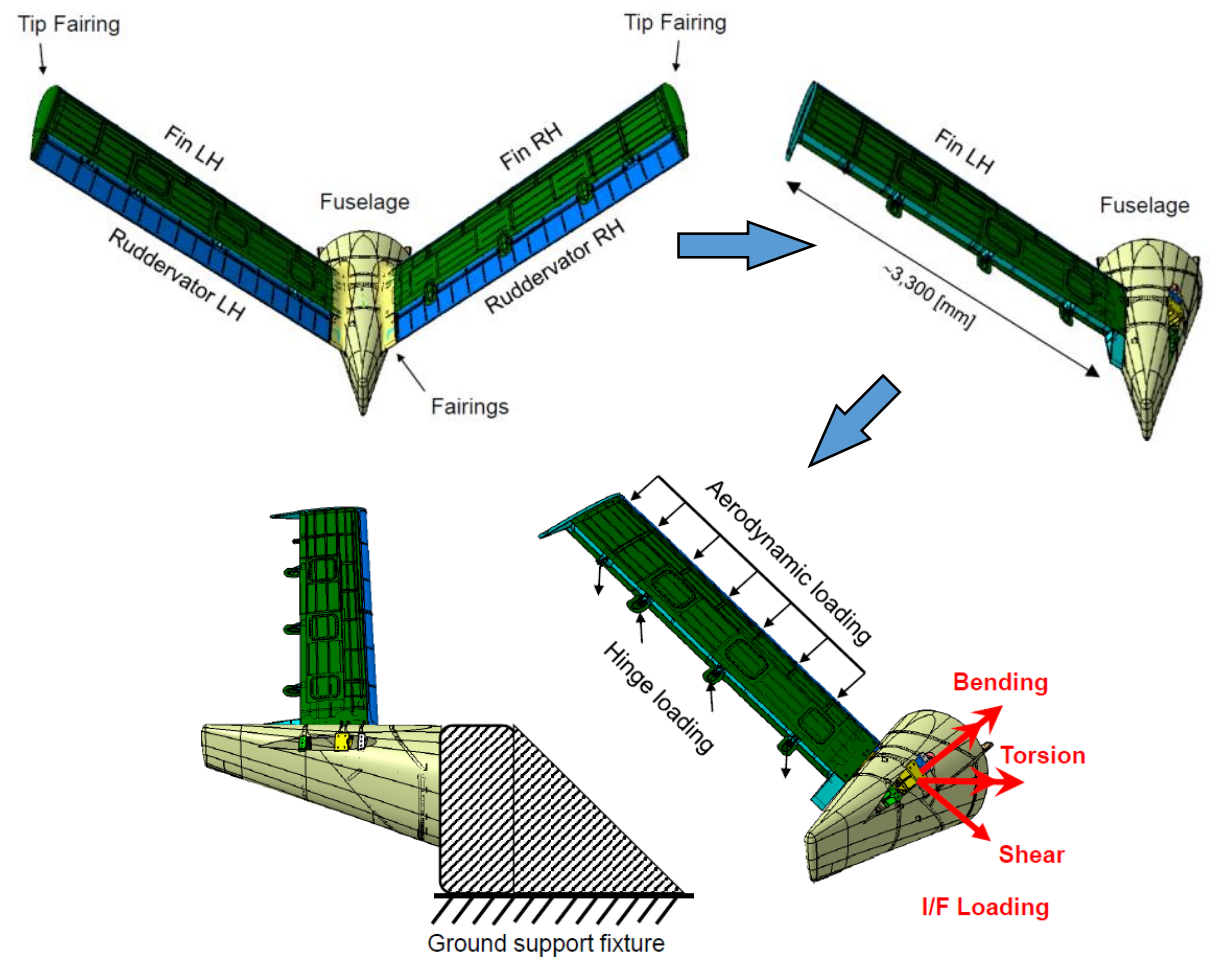

Fig. 2. The basic conception of the test

The designed ground support with the attached test article si shown is shown in Figure 4. The fuselage is turned so that the tail has a horizontal position to the ground, which allows easier load application. The walkways will be designed around the test rig to guarantee accessibility to the critical points of the structure. The design of the walkways guarantees accessibility for all measurements perform during the test and for performing all necessary artificial damages and inspections. 


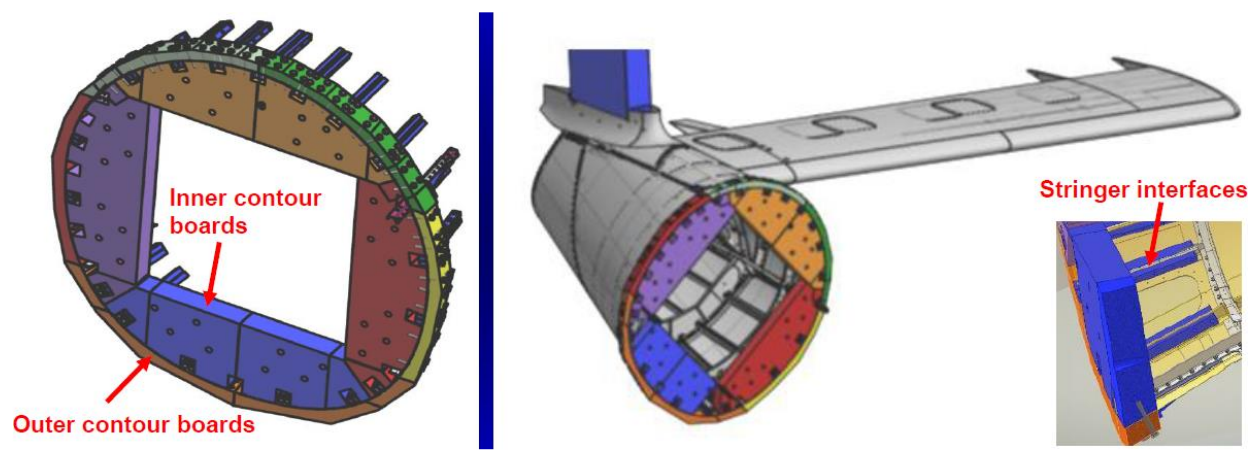

Fig. 3. Attachment by Segment of Contour Boards

Fig. 4. Design of the test rig

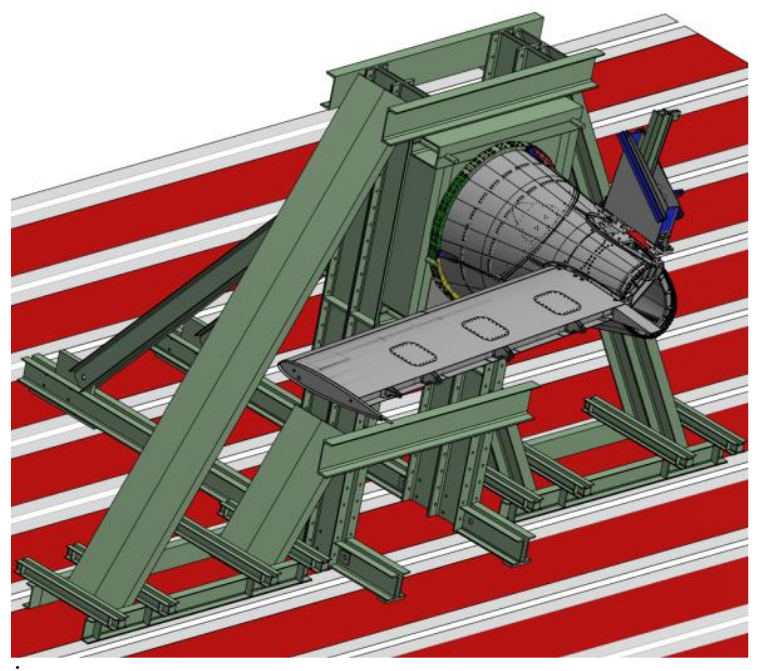

\section{Load application}

\subsection{Fin LH loading}

Clamps with contour boards will be used for the transfer of the aerodynamic loading on the Fin. The weight of the contour boards will be balanced. The basic design of aerodynamic loading via clamps with contour boards is shown in Figure 5. The clamps with contour boards are loading the rib wings and Front Spar of the Fin only.
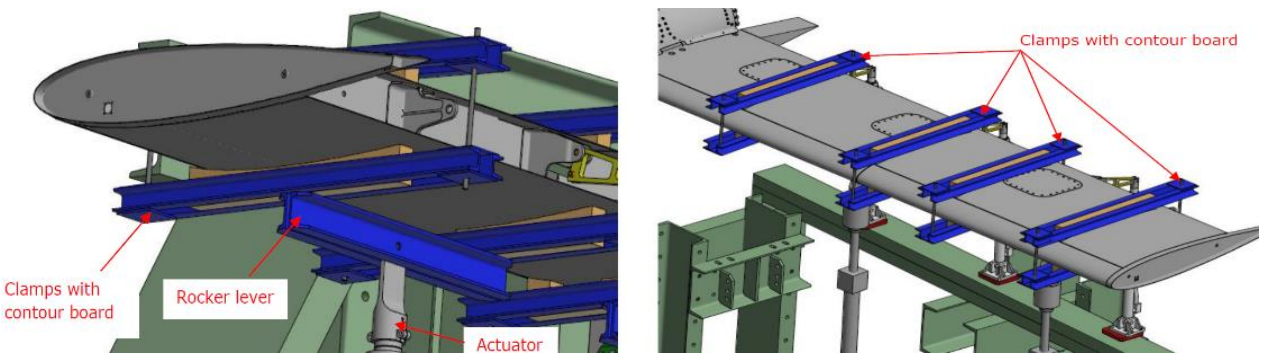

Fig. 5. Basic design of Fin LH aerodynamic loading 


\subsection{Hinge loading}

The aerodynamic load of the Ruddervator will be provided via separate hinges. Simultaneously with the aerodynamic load, the forces from the actuators via the dummy of the Ruddervator will be introduced to the hinges. In this case, the actuator will be replaced via a calibrated rod. The basic principle and basic design of the hinge loading are shown in Figure 6.

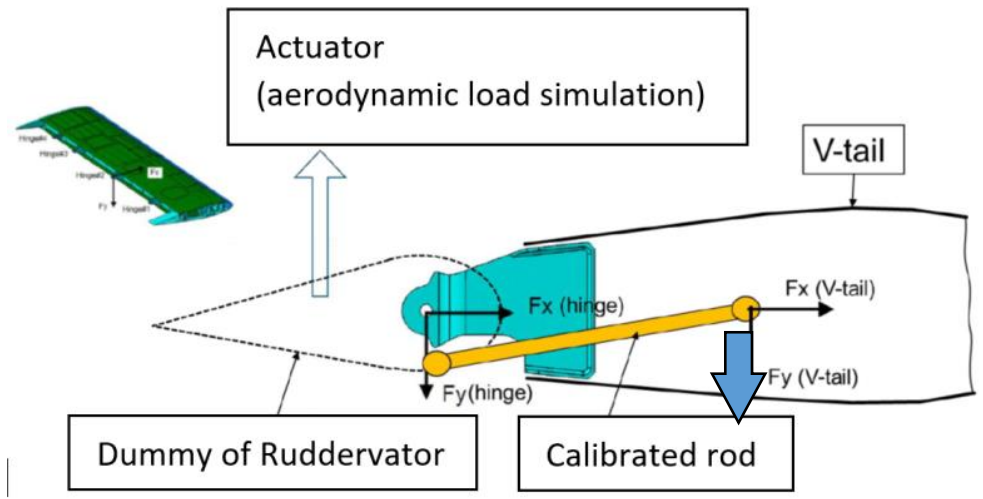

Fig. 6. Design of the Hinge loading with dummy of elevator

\subsection{Dummy of RH Tail}

The proposed solution of the loading introduction to the dummy $\mathrm{I} / \mathrm{F}$ is shown in Figure 7 and Figure 8. The tail on the RH will be substituted with a dummy for I/F loading, see Figure 7. The dummy will have an identical attachment to the fuselage as the left Tail, see Figure 8. Three loading actuators will be used to implement relevant forces at the attachment for each load case.
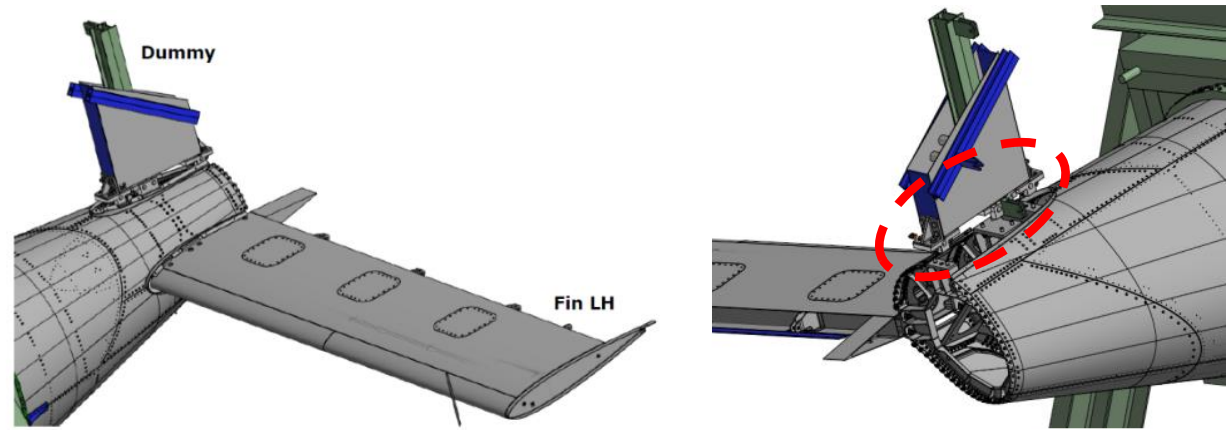

Fig. 7. Basic view of the RH Fin dummy 


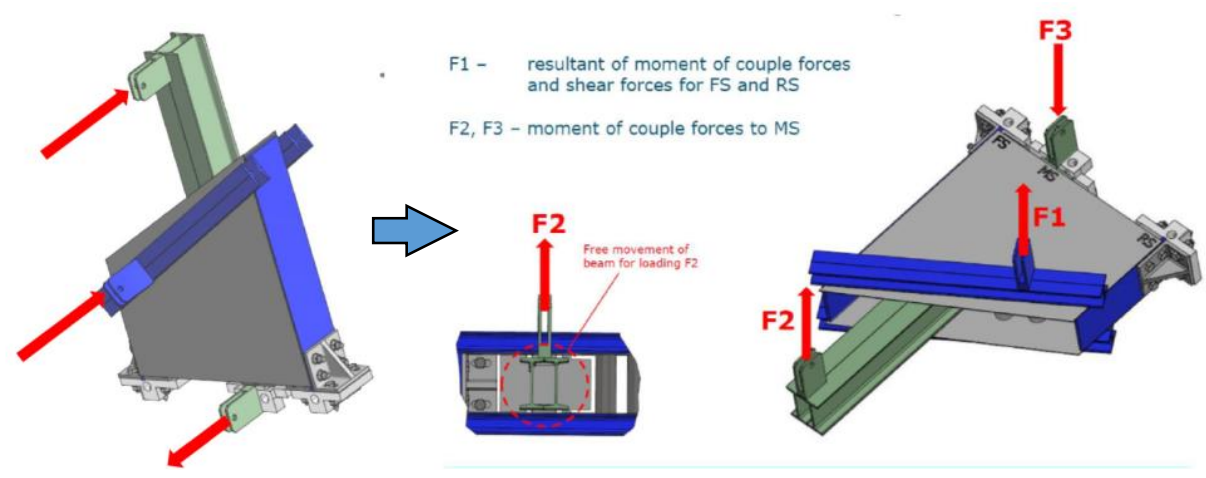

Fig. 8. Loading of the RH Fin dummy

\section{Control system}

The multipurpose test rig has to be accompanied by powerful and flexible control system to ensure reliable and safe operation of the test. The system MTS Aero ST controller with AeroPro $^{\mathrm{TM}}$ software will be used for the test. The AeroPro software package provides aerospace structural engineers with a state-of-the-art user interface and a flexible software environment. The software meets today's increasing demands for high channel count, data integrity, and online data monitoring and display. The control system must be able to control the test under all conditions and it must offer in addition to the standards elements of regulation extra features to allow mastering challenging control steps. The system provides safety of the test specimen in case of failure. It monitors the condition of the test specimen and reacts to its changes according to rules set by the operator. It carries out immediate unloading in reaction to selected events. During the whole test, it continuously saved all measured data and sequence of test events.

\section{Data acquisition}

Combination of strain gauges and deflection measurement will provide the complex stiffness analyses of the test specimen during the strength test.

\subsection{Strain gauges measurement}

MTS FlexDACTM20 Data acquisition system will be used for the strain gauges measurements. The MTS FlexDAC 20 Data Acquisition System provides a highperformance solution for acquiring data through strain and bridge-based devices during mechanical testing. Fast processing speeds and a high-channel-count capacity make the MTS FlexDAC 20 system ideal for evaluating the behaviour of full-scale structures under load.

\subsection{Deflection measurement}

Defůection and deformation of the tested structure will be ansured by both contactless optical and wire sensors. For optical measurements the two systems will be applied:

- Digital image correlation (DIC) system makes it possible to measure the fulfield displacement measurements (the commercial Dantec Q-400 and ARAMIS devices).

- Optical photogrammetry system TRITOP for precise three-dimensional measurement of descrete structural points at quasi-static conditions. 
Based on this information, TRITOP is capable of calculating 3D displacements and deformations of objects and components.

For wire deformation mesurements of discrete points incremental sensors (deflectometers) and draw wire sensors will be applied.

\section{Summary}

The paper presents the main objectives of the TAILTEST project and the design of the multipurpose test rig represents capableto to simulate and introduce the different load cases and structural stiffness during verification of the helicopter ruddervator. Next step of the work will be load cases definition, test conduction and evaluation, and numerical verification.

\section{References}

1. Development of a multipurpose test rig and validation of an innovative rotorcraft vertical tail (TAILTEST). Horizon 2020 / Clean Sky JU / Call: H2020-CS2-CFP092018-02 / Topic: JTI-CS2-2018-CFP09-AIR-02-74 / Project number: 865123, 2019, https://www.horizon-tailtest.eu/.

2. R. Růžek, J., Běhal, Certification programme of airframe primary structure composite part with environmental simulation, Int. J. of Fatigue 31(6), pp. 1073-1080 (2009) https://doi.org/10.1016/j.ijfatigue.2008.05.028.

3. R. Růžek, R., M. Kadlec, K. Tserpes, E. Karachalios, Monitoring of compressive behaviour of stiffened composite panels using embedded fibre optic and strain gauge sensors, Int. J.of Structural Integrity, 8(1), pp. 134-150. (2017) https://doi.org/10.1108/IJSI-11-2015-0052

4. R. Růžek, J. Šedek, M. Kadlec, P. Kucharský, Mechanical behavior of thermoplastic rib under loading representing real structure conditions, in Proceedings of the EAN 2016 - 54th International Conference on Experimental Stress Analysis, Srní, Czech Republic, 30 May-2 June 2016, (2016) EID: 2-s2.0-84986296610

5. D.M.J. Peeters, F.X. Irisarri, Ch. Groenendijk, R. Růžek, Optimal design, manufacturing and testing of non-conventional laminates, Composite Structures, 210, pp. 29-40, (2019) DOI: 10.1016/j.compstruct.2018.10.062

6. V. Snop, V. Horak, Testing Overview of the EADN Samples, in Proceedings of the P. Wölcken, M. Papadopoulos (eds) Smart Intelligent Aircraft Structures (SARISTU). Springer, Cham. (2016) https://doi.org/10.1007/978-3-319-22413-8_4

7. D. Drezga et al. Winglet Design, Manufacturing, and Testing, in Proceedings of the Wölcken P., Papadopoulos M. (eds) Smart Intelligent Aircraft Structures (SARISTU). Springer, Cham. (2016) https://doi.org/10.1007/978-3-319-22413-8_13

8. R. Růžek, R. Doubrava, J. Raška, Wing repair using an adhesively bonded boron composite patch - design and verification, International Journal of Structural Integrity, 6(2), pp. 259-278, (2015) https://doi.org/10.1108/IJSI-10-2013-0027

\section{Acknowledgement:}

This paper is supported by European Union's Horizon 2020 research and innovation programme under the call H2020-CS2-CFP09-2018-02, the grant agreement No 865123, project TAILTEST - Development of a multipurpose test rig and validation of an innovative rotorcraft vertical tail. 